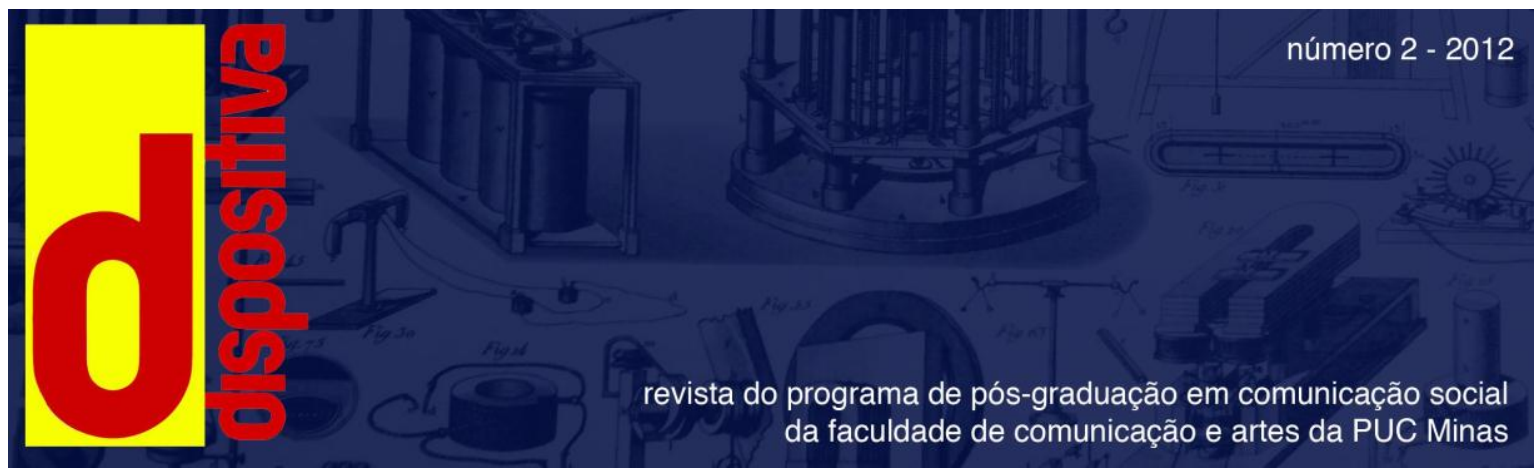

\title{
Imagens que vinculam: espetáculo, entretenimento e performance no YouTube// Images that entail show, entertainment and performance in the YouTube ${ }^{1}$
}

\author{
Carlos Magno Camargos Mendonça ${ }^{2}$ e Tiago Barcelos Pereira Salgado ${ }^{3}$
}

\section{Resumo}

O advento e o avanço das mídias comunicacionais nas sociedades contemporâneas tem reconfigurado os modos de estar junto socialmente e alterado o regime do visível. Atentando para as transformações nos modos de ver e de se relacionar, ressaltamos a dimensão espetacular e entretenida implicada na performance dos agentes sociais. A prática performática, por essa via, tem se configurado segundo à lógica mediática e mercadológica, em que sujeitos em (inter)ação se colocam frente ao olhar alheio visando conquistar atenção e alcançar a visibilidade propiciada pelos media. Neste artigo, atemo-nos à ambiência midiática configurada pela internet, mais precisamente os vídeos de Felipe Neto no YouTube, buscando compreender de que modo as imagens possibilitam vinculações sociais.

Palavras-chave: Entretenimento. Espetáculo. Felipe Neto. Performance. YouTube.

\begin{abstract}
The advent and advancement of communication media in contemporary societies has reconfigured the ways of being together socially and changed the visible regime. Paying attention to the changes in ways of seeing and relating, we highlight the spetacular and entertained dimension involved in the performance of social agentes. The performative practice, thereby, has been been configured according to the media and marketing logic, in wich subjects in (inter)action square up themselves to others aiming to achieve attention and the visibility afforded by the media. In this paper, we stick to the media ambience set by the internet, more precisely to Felipe Neto's videos on YouTube, trying to understand how images enable social links.
\end{abstract}

Keywords: Entertainment. Felipe Neto. Performance. Spetacle. YouTube.

\footnotetext{
1 Versão revista e atualizada de artigo apresentado no GT "Entretenimento Digital" do VI Simpósio Nacional da ABCiber (Associação Brasileira de Cibercultura).

2 Professor do Programa de Pós-Graduação em Comunicação Social da Universidade Federal de Minas Gerais (UFMG)

${ }^{3}$ Mestrando do Programa de Pós-Graduação em Comunicação Social da UFMG. Integrante do grupo de pesquisa Poéticas da Experiência - subgrupo Performances. Bolsista do CNPq Dispositiva 


\section{Introdução}

Compreender a sociedade contemporânea tem sido uma tarefa árdua e complexa sobre a qual diferentes pensadores de vários campos do conhecimento tem se dedicado. Alguns fenômenos, mais próximos ao nosso campo de estudos, a Comunicação, tem se tornado característicos da cena atual. Dentre as várias manifestações simbólicas que repercutem nos modos de estar juntos, podemos evidenciar a espetacularização da vida e o processo de mediatização das sociedades. Nesse contexto, em que os media assumem a gestão de um modus operandi próprio ao nosso tempo, que atravessa as múltiplas instituições sociais, observamos a proliferação constante de imagens.

Atentando para a expansão dos media, proporcionada, preferencialmente, pelo avanço das tecnologias de comunicação e informação e sua respectiva acessibilidade às pessoas comuns, percebemos um cenário em que as vidas tem se tornado mercadorias em circulação, prontas para o consumo (BAUMAN, 2007). Mais do que concordar ou discordar de posições marxistas que enfatizam uma certa submissão dos indivíduos ao capital, mesmo que possamos mencionar múltiplas formas de resistência à lógica mercantil, nosso intuito é constatar e problematizar os modos interacionais permeados por imagens. Produções imagéticas que ultrapassam os limites do suporte e organizam estatutos e regimes de visibilidade e sociabilidade singulares.

Nestas circunstâncias de alta visibilidade (HERSCHMANN, 2005), o que vale é a aparência. O êxito ou o fracasso dos sujeitos depende menos do que eles são ou possuem do que aparentam ser e ter (DEBORD, 1997). Administrar a si mesmo como marca e gerir a própria imagem atestam narrativas de diversos "eus" que visam conquistar a visibilidade propiciada pelos media. Performar diante de vários olhares tem sido mais do que exibir-se frente às câmeras. Essa prática exibicionista tem se estruturado como um direito dos membros da "sociedade da imagem" e uma condição de existência (BRUNO, 2004), de modo que quem não se mostra, não se permite ser visto, não é lembrado, não existe socialmente, ainda que o seja biologicamente.

Com essas questões, buscamos problematizar a cena contemporânea, tendo em vista a lógica midiática e mercadológica atual que a afetam. Nos voltamos, de maneira privilegiada, para as performances que detêm uma dimensão espetacular e entretenida reforçada pelos media, mais especificamente para práticas sociais em evidência em vídeos no YouTube.

\section{Por um outro regime do visível: visibilidade em um contexto mediatizado}


Ao pensar sobre a reconfiguração do conceito de visibilidade sob uma visão de uma teoria social dos meios de comunicação, Thompson $(2008,2010)$ parte da premissa de que o surgimento de uma visibilidade diferente da que se apreendia anteriormente está definitivamente relacionado a diferentes maneiras de agir e interagir trazidas com os media. Para compreender o cenário contemporâneo, Thompson $(2008,2010)$ propõe analisar os meios de comunicação em sua relação com as formas de interação que eles tornam possíveis e das quais são parte.

De acordo com esse pensamento, o avanço das mídias comunicacionais, ou seja, a mediatização, transformou a natureza da interação social ao criar novos campos de ação e interação, em que podemos observar novas formas de visibilidade, não mais ligadas, necessariamente, a um contexto de copresença (interação face-a-face). Por mediatização, entendemos o modelo não completo e não hegemônico em vias de implementação nas sociedades contemporâneas em que os media se apresentam como o processo interacional de referência (BRAGA, 2006; VERÓN, 2001). A lógica de mediatização, portanto, diz respeito ao modo como os processos sociais "da mídia" passam a incluir e abranger os demais processos, absorvendo-os, redirecionando-os e lhes dando outro desenho. A mediatização aparece como processo social gerador de tecnologia ou gerado pela tecnologia. Em processo de mediatização, como argumenta Braga (2006, p. 6), há uma "necessidade de tecnologia" por si mesma.

A mediatização resulta, assim, da "evolução de processos mediáticos que se instauram nas sociedades industriais [...] e que chamam a atenção para os modos de estruturação e funcionamento dos meios nas dinâmicas sociais e simbólicas.” (FAUSTO NETO, 2008, p. 90). Os media são tomados como ambiências que operam mediações entre partes da sociedade, entre outras dinâmicas de diferentes campos e entre as práticas sociais. Eles assumem uma referência importante na maneira de ser da própria sociedade e nas práticas interacionais entre atores sociais e instituições (HJARVARD, 2012), de modo que deixam de ser apreendidos simplesmente pela função de auxiliares dessas dinâmicas, uma vez que operam preferencialmente transformando-as de múltiplas formas e em diferentes aspectos.

Olhando para um dos lados desse processo, Thompson (2008, p. 23) denomina a (re)configuração espaço-temporal desencadeada pelos media de simultaneidade desespacilizada, em que 
pessoas distantes poderiam fazer-se visíveis praticamente no mesmo instante; poderiam ser ouvidas no exato momento em que falavam; vistas no mesmo momento em que agiam, embora não compartilhassem a mesma esfera espacial com os indivíduos para quem se faziam visíveis".

A exemplo desse contexto em que notamos uma liberação da necessidade dos indivíduos de dividirem um mesmo referencial de espaço e de tempo, ao qual Thompson (2008) conceitua como visibilidade mediada, podemos citar: os vídeos no YouTube, o MSN, o Skype, o AO VIVO, entre outros. É válido ressaltar que a qualificação "mediada" conferida pelo autor à visibilidade implica em redundância, uma vez que há sempre uma mediação em operação, seja ela dada pelo olho ou por dispositivos técnicos - esses últimos aos quais o teórico faz menção e compreende enquanto mediadores da visibilidade na atualidade.

Ao relacionarmos a questão da visibilidade com as formas mediadas de comunicação, questionamos juntamente com Thompson (2010): o que é ser visível? "Visível é aquilo que pode ser visto.” (p. 20). A visão, enquanto sentido do corpo humano, está relacionada diretamente com nossas possibilidades físicas. A princípio, a visibilidade é recíproca: vemos o que está dentro do nosso campo de visão, de modo que os limites do que podemos ou não ver são dados pelas características espaciais e temporais do aqui e agora - no que diz respeito ao aspecto biológico. Apreendemos, dessa maneira, que

[...] não podemos ver além de uma certa distância [...]; não podemos ver sem uma certa quantidade de luz [...]; não podemos ver o futuro ou o passado. [...] A visibilidade comum é sempre localizada: aqueles que são visíveis para nós são aqueles que compartilham conosco a mesma referência espaço-temporal (THOMPSON, 2010, p. 20).

Esse fenômeno é descrito pelo autor como a visibilidade localizada da copresença.

O surgimento da visibilidade mediada estaria relacionado, segundo Thompson (2010) ao desenvolvimento dos meios de comunicação nos séculos XIX, XX e XXI - implicados, como ressaltamos anteriormente, no processo de mediatização da sociedade, como destacado por Verón (2001) e Braga (2006) -, em que notamos a liberação da visibilidade das condições temporais do aqui e agora. Nesse aspecto, as técnicas de gravação e transmissão, recorrentes nos dispositivos técnicos contemporâneos, ampliam espacialmente e alargam temporalmente nosso campo de visão. Com esse avanço dos dispositivos técnicos, que podem ser pensados como extensões do homem ${ }^{4}$, o caráter recíproco da visibilidade é alterado. Ver, como destaca

\footnotetext{
${ }^{4}$ Ponto de vista ancorado nas ideias de Marshall McLuhan em seu livro Os meios de comunicação como extensões do homem. São Paulo: Editora Cultrix, 2002. 
Thompson (2010) nunca é pura visão, uma vez que ao visual se associam outros modos de percepção, de modo que temos o audiovisual e o texto-visual.

Para exemplificar esse contexto atual marcado pela visibilidade mediada tecnicamente, Thompson (2010) faz menção a alguns escândalos políticos e chama a atenção para uma sociedade da auto-promoção, em que se torna possível e cada vez mais comum líderes políticos e outros indivíduos aparecerem diante de públicos distantes e desnudarem algum aspecto de si mesmos ou de sua vida pessoal, ao que o autor denomina intimidade mediada (pelos media), ou seja, uma forma íntima de apresentação pessoal livre das amarras da copresença. Desse modo, “conquistar visibilidade pela mídia é conseguir um tipo de presença ou de reconhecimento no âmbito público que pode servir para chamar a atenção para a situação de uma pessoa ou para avançar a causa de alguém.” (THOMPSON, 2008, p. 37, grifo nosso).

A conquista de visibilidade, como pretendemos destacar a seguir, imersa nos interstícios das fronteiras cambiantes entre os domínios público ${ }^{5}$ - ascensão da visibilidade mediada - e privado - surgimento da privacidade desespacializada -, se entrelaça ao tecido social costurado, operacionalmente, pela performance social ${ }^{6}$ do agentes. Tendo isso em vista, buscamos destacar agora a dimensão espetacular e entretenida que as performances sociais adquirem em decorrência do processo de mediatização. Procuramos sublinhar, ainda, de que maneira o espetáculo e o entretenimento se veem mutuamente imbricados à lógica mercadológica capitalista.

\section{Espetáculo, entretenimento e performance}

O conceito de espetáculo foi introduzido pelo pensador e diretor de cinema francês Guy Debord no livro La Société du Spectacle (A Sociedade do Espetáculo) ao final da década de 1960. O quadro teórico proposto pela perspectiva crítica ao espetáculo auxilia nossa investigação a situar o nosso objeto de análise em um contexto de capitalismo avançado. Uma cena social e econômica que privilegia a acumulação e é marcada pela transformação de objetos e experiências em mercadorias. Disso decorre, de acordo com Debord (1997), a substituição do mundo sensível por uma seleção de imagens que se pretendem mostrar enquanto uma possível realidade. O espetáculo, portanto, não se apresenta separado da

\footnotetext{
${ }^{5}$ Conferir a discussão entre público e privado por Hanna Arendt em Thompson (2010).

${ }^{6}$ Utilizamos o termo performance social pra diferenciarmos a prática que temos enfatizado daquela realizada por artistas, a performance artística (performance art).

Dispositiva

v. 1 n. 2

nov.2012 / abr.2013
} 
sociedade, mas sim como parte integrante dela, "uma relação social entre pessoas, mediada por imagens." (DEBORD, 1997, p. 14).

$\mathrm{Na}$ abordagem debordiana, o ser teria sido deslocado para o ter que, por sua vez, teria se deslocado para o parecer ou aparecer. Ao remontar à essa conceituação proposta por Debord (1997), Paula Sibilia $(2008,2010)$ argumenta que "viver é encenar". Tematizando o fenômeno de espetacularização da vida, Sibilia (2008) evidencia que o indivíduo é o que se vê e como se deixa ver - argumentação que se aproxima da perspectiva de Goffman (1985), ainda que a autora não cite o teórico. Segundo essa visão, o indivíduo cria performances visuais de si que integram um repertório social de imagens. Nesse sentido, performar é colocar-se frente ao olhar alheio, de modo que a existência é validada ou legitimada pela observação do outro.

Aproximando essa perspectiva do nosso objeto, compreendemos que os vídeos de Felipe Neto postados no YouTube clamam por acessos e compartilhamentos. Assim, um dos posicionamentos adotados por Felipe poderia ser chamado de eu performático espetacular para estabelecermos um diálogo com as proposições das múltiplas faces de eu sugeridas por Sibilia (2008): eu narrador, eu privado, eu visível, eu atual, eu autor, eu personagem e eu espetacular.

Nossa proposição diz respeito à configuração de um eu palatável que, ao buscar a visibilidade, pretende ser consumido e digerido pelo olhar dos outros e que ultrapassaria os limites do "exibir-se ao extremo", como pontuado por Schechner (2003) e retomado por Sibilia (2010). Seria, também, como sugere a autora, um eu forjado na arte de se mostrar fazendo e sendo: "A experiência de si como um eu se deve, portanto, à condição de narrador sujeito: alguém que é capaz de organizar sua experiência na primeira pessoa do singular." (SIBILIA, 2008, p. 31). Tal observação aproxima-se bastante da performance que Felipe Neto realiza em seus $v \log s$, em que ele assume a condição de um narrador sujeito que organiza sua experiência em torno da capacidade de ação e fala de um "eu".

O tipo de produção audiovisual que Felipe Neto realiza, como também de outros usuários do YouTube, como PC Siqueira, Kéfera Buchmann, entre outros, tem sido denominada de vlog. Essa nomeclatura faz menção aos blogs em forma de vídeo que são postados nas redes online. O termo blog nomeia uma prática de exposição da intimidade que remonta aos diários íntimos, redigidos por seus donos, aos quais somente eles teriam acesso. Em forma de pequenos textos, chamados de posts, os usuários podem dar a ver um relato individual de suas vidas cotidianas e que chama a curiosidade de outros em função do 
"segredo" que conteriam, bem como do caráter de confissão e desabafo (ROTHMAN, 2012; SIBILIA, 2008).

Esse modo de exibição de um eu que se pretende cativante recorre ao humor e a crítica como estratégias de conquista do olhar alheio. Juntamente a esses recursos, os performers, agentes em ação com influência sobre o outro, que dão a ver uma impressão de quem pretendem ser (GOFFMAN, 1985), ancoram-se na dimensão entretenida e mercadológica colada à lógica midiática. Visando reter a audiência, os vlogs tem se profissionalizado. Os equipamentos empregados, como câmeras de vídeo, por exemplo, são cada vez mais profissionais, garantindo alta resolução para o conteúdo a ser veiculado (ROTHMAN, 2012). Muitos dos vídeos se valem de estúdios e profissionais de edição que trabalham para assegurar a qualidade do material. De meros amadores e ordinários, os performers tem se apresentado como celebridades que sabem o que fazem e para quem fazem.

A respeito da relação entre performance e entretenimento, Carlson (2010) destaca que uma das possibilidade de compreensão da performance é entender que essa prática se configura como uma atividade de entretenimento conscientemente produzida para uma audiência. Entreter, nesse sentido, se remontarmos a raiz latina do termo - inter (entre) e tenere (ter) -, significa colocar-se entre a audiência visando seu divertimento. $\mathrm{O}$ entretenimento, como argumentam Herschmann e Kischinhevsky (2008), está diretamente vinculado à sociedade do espetáculo (DEBORD, 1997), que prima por investir na imagem, na aparência, na visibilidade. Herschmann e Kischinhevsky (2008) compreendem que as narrativas performáticas dos atores sociais são exibidas em uma nova arena: a arena midiática.

Com isso, percebemos que a performance requer a colocação de uma ação, de uma prática, entre o performer e a audiência, de modo que um assuma uma responsabilidade para com o outro. Entreter, dessa maneira, é um recurso de mediação entre performer e audiência. A relação estabelecida entre ambas as partes durante a performance opera, então, pelo reconhecimento por parte da audiência daquilo que lhe é próprio no performer.

Contemporaneamente, a internet tem se mostrado como o locus prioritário para a performance social dos sujeitos. Ao disponibilizar ferramentas de fácil manuseio, essa ambiência midiática possibilita que usuários comuns se expressem e se deem a ver a muito outros usuários em função da visibilidade implicada no próprio meio. Dessa maneira, o indivíduo comum passa da possibilidade de ingressar nos media para ele mesmo ser sua própria mídia e criar sua própria audiência. Ao se tornarem atores de suas próprias vidas, os sujeitos sociais se constituem no ato mesmo de se fazerem visíveis ao outro, ou seja, por meio da exterioridade, performances e espetáculos de si mesmos (BRUNO, 2004). 
Tendo dito isso, o nosso olhar se volta, na análise que propomos, para a performance de Felipe Neto no YouTube. A partir dos vídeos de Neto, buscamos compreender de que modo o expor-se publicamente no YouTube se relaciona às reconfigurações do visível ocasionadas pelo processo de mediatização e constitui um acervo de imagens que possibilitam vinculações sociais.

\section{Felipe Neto em performance o YouTube}

Felipe Neto nasceu em 21 de janeiro de 1988 na cidade do Rio de Janeiro. Durante a adolescência, fez cursos de teatro e atuou como ator amador em alguns espetáculos teatrais. Em 2007, escreveu sátiras e reflexões humoradas para o blog Controle Remoto ${ }^{7}$. A criação desse site se deu em virtude da notoriedade que Neto obteve com o avatar " "Cap_Sparrow", um dos administradores do portal de séries americanas IsFree.tv (ARRUDA, 2011; CONTROLE REMOTO, 2010). Em 19 de abril de 2010, com 22 anos, Felipe criou o seu primeiro canal $^{9}$ no YouTube, o Não Faz Sentido! ${ }^{10}$. Em 21 de maio do mesmo ano, Neto inaugurou o seu segundo canal, o Felipe Neto Vlog ${ }^{11}$. O YouTube, criado em fevereiro de 2005, permite a diferentes usuários compartilharem conteúdo audiovisual por meio do upload e visualização de imagens produzidas por outros usuários.

O primeiro canal de Neto aborda temas da atualidade e remete críticas a comportamentos e atitudes de artistas e da população em geral. O segundo canal, por sua vez, nomeia-se vlog e busca destacar aspectos pessoais da vida de Felipe Neto, bem como um making-of do primeiro canal. Os vídeos de Neto ganharam notoriedade e são alguns dos mais acessados no YouTube (FELIPE NETO TEAM, 2012; WIKIPÉDIA, 2011).

Em função do sucesso dos vídeos e dos temas neles abordados, que reverberam em outros ambientes midiáticos, tais como: Facebook, Orkut, Twitter, entre outras redes sociais; Felipe Neto recebeu o convite de duas emissoras de televisão para participar de programas televisivos. Em 2011, Felipe participou do quadro Sem Noção no programa Esporte

\footnotetext{
${ }^{7}$ Disponível em: <http://controleremototv.blogspot.com.br> Acesso em: 19 jun. 2012.

${ }^{8}$ Termo proveniente do hinduísmo, referindo-se à manifestação de uma divindade ou corporificação de uma alma na terra; a encarnação de uma divindade, ideia ou pessoa. Em computação, o termo tem sido utilizado para designar um ícone, figura ou nome de usuário que representa uma pessoa em jogos de computador, videogames, fóruns e chats na internet etc. (OXFORD DICTIONARY, 2012).

${ }^{9} \mathrm{O}$ termo "canal" é utilizado pelo site YouTube para nomear uma ou mais páginas pessoais de usuários cadastrados no site (perfis). Em cada página, os usuários podem postar vídeos que eles mesmos realizaram ou compartilhar vídeos de outros usuários, bem como postar informações sobre si e o canal. Usuários que se inscrevem (subscribe) em determinado canal podem postar comentários nele.

${ }^{10}$ Disponível em: <http://www.youtube.com/user/felipeneto> Acesso em: 18 out. 2011.

${ }^{11}$ Disponível em: <http://www.youtube.com/user/felipenetovlog> Acesso em: 18 out. 2011.

Dispositiva

v.1 n.2

nov.2012 / abr.2013
} 
Espetacular da TV Globo, como também dos programas Será que faz sentido? e Até que faz sentido, veiculados pelo canal de televisão Multishow. A proposta desse último programa é a seguinte: "Felipe vai levantar suas críticas sobre coisas que pra ele não fazem sentido, mas depois vai às ruas procurar saber das pessoas o que elas pensam sobre o assunto. Não faltarão debates carregados do humor ácido já conhecido desse rapaz que hoje é uma celebridade da web." (MULTISHOW, 2011). Em 06 de abril de 2012, Felipe Neto retornou com a segunda temporada desse programa televisivo. Em 2010, na mesma emissora, Felipe fez parte da série brasileira Na Fama e Na Lama. Nesse mesmo ano, ele foi entrevistado pelo apresentador Jô Soares. Neto participou, ao longo dos anos, de diversas campanhas publicitárias para diferentes clientes, dentre os quais podemos citar: Caixa Econômica Federal, Credicard e Wise Up. Com relação às premiações, Felipe Neto venceu os prêmios "Video Music Brasil", na categoria "Web Star" (2010), e "Os Melhores da Websfera", na categoria "Vem, Gente!" (2011), sendo indicado como "Personalidade do Ano" no " $4^{\underline{0}}$ Prêmio Tudo de Bom!". Atualmente, ele tem se dedicado à Parafernália ${ }^{12}$, produtora e canal de humor no YouTube criado em 2011 (FELIPE NETO TEAM, 2012; WIKIPÉDIA, 2011).

A escolha dos vídeos de Felipe Neto no YouTube se justifica pelo fato do site receber uma postagem de 60 horas de vídeos por minuto; 700 vídeos serem compartilhados no Twitter por minuto; possuir 800 milhões de usuários únicos ao mês; e ter uma média de 4 bilhões de vídeo assistidos por dia (ROTHMAN, 2012). Com relação aos vídeos de Felipe, eles são acessados por milhões de usuários brasileiros de ambos os sexos compreendidos na faixa etária de 13 a 24 anos, como podemos observar nas seguintes tabelas ${ }^{13}$ :

TABELA 1

Dados estatísticos do canal Não faz sentido

\begin{tabular}{|c|c|c|c|c|}
\hline Data de ativação & Inscrições & Vídeos postados & Duração dos vídeos & Video Views \\
\hline $15 / 05 / 2006$ & 951.322 & 39 & 2 a 15 minutos & 129.937 .091 \\
\hline \multicolumn{5}{r}{ FONTE: Elaborada pelo autor }
\end{tabular}

TABELA 2

Dados estatísticos do canal Felipe Neto Vlog

\footnotetext{
${ }^{12}$ Disponível em: <http://www.youtube.com/user/canalparafernalia> Acesso em: 19 jun. 2012.

${ }^{13} \mathrm{O}$ YouTube disponibiliza uma ferramenta de aferição estatística do perfil da audiência de cada vídeo postado uma vez que o usuário que acessa o conteúdo tenha efetuado o login. Os dados que podem ser obtidos por meio desse recurso são: total de visualizações para o vídeo escolhido; número de usuários que gostam do vídeo; número de usuários que não gostam do vídeo; número de comentários; número de usuários que adicionaram o vídeo como favorito; eventos de relevância (primeira inscrição, primeiro acesso por meio de um dispositivo móvel etc.) e perfil da audiência em relação ao gênero, faixa etária e país de acesso. Os dados mencionados nas tabelas se referem ao dia 08 de julho de 2012. 


\begin{tabular}{|c|c|c|c|c|}
\hline Data de ativação & Inscrições & Vídeos postados & Duração dos vídeos & Video Views \\
\hline $21 / 05 / 2010$ & 280.580 & 22 & 4 a 10 minutos & 16.191 .168 \\
\hline \multicolumn{5}{|r}{ FONTE: Elaborada pelo autor }
\end{tabular}

A breve análise que procuramos realizar neste artigo atenta apenas para os vídeos dispostos no canal Felipe Neto Vlog, mais especificamente para aqueles que foram classificados e nomeados por Felipe na categoria "Coisas da Madrugada", como podemos sintetizar na seguinte tabela:

TABELA 2

Dados estatísticos dos vídeos "Coisas da Madrugada" - canal Felipe Neto Vlog

\begin{tabular}{|c|c|c|c|c|c|c|c|}
\hline Nome do vídeo & Data & Duração & Visualizações & Likes & Deslikes & Comentários & Favoritos \\
\hline Desabafo e Coisas da Madrugada & $07 / 07 / 10$ & $8: 34$ & 1.410 .646 & 17.530 & 764 & 8.522 & 1.230 \\
\hline Coisas da Madrugada 2 & $09 / 08 / 10$ & $9: 35$ & 777.698 & 14.767 & 460 & 4.827 & 743 \\
\hline $\begin{array}{c}\text { Coisas da Madrugada - } \\
\text { VMB e artistas }\end{array}$ & $18 / 09 / 10$ & $5: 40$ & 616.485 & 10.511 & 602 & 708 \\
\hline $\begin{array}{c}\text { Coisas da Madrugada - } \\
\text { Jô, palavrões e iPod }\end{array}$ & $19 / 10 / 10$ & $9: 28$ & 826.206 & 11.354 & 371 & 7.151 \\
\hline $\begin{array}{c}\text { Coisas da Madrugada - } \\
\text { Vlog Oficial }\end{array}$ & $24 / 10 / 10$ & $6: 03$ & 371.404 & 8.364 & 362 & 2.208 & 436 \\
\hline $\begin{array}{c}\text { Coisas da Madrugada - } \\
\text { Cadê minha carta de Hogwarts? }\end{array}$ & $02 / 11 / 10$ & $7: 47$ & 784.980 & 15.665 & 616 & 6.745 \\
\hline $\begin{array}{c}\text { Coisas da Madrugada - } \\
\text { ELLLEECTABUUUUZZZ }\end{array}$ & $04 / 11 / 10$ & $7: 17$ & 1.646 .711 & 16.223 & 1.645 & 6.479 \\
\hline $\begin{array}{c}\text { Coisas da Madrugada - } \\
\text { EU VOLTEI }\end{array}$ & $04 / 12 / 11$ & $9: 49$ & 830.392 & 19.417 & 1.076 & 5.470 \\
\hline $\begin{array}{c}\text { Coisas da Madrugada - } \\
\text { O Fim do Não Faz Sentido? }\end{array}$ & $24 / 02 / 12$ & $10: 03$ & 457.379 & 15.385 & 492 & 1.168 \\
\hline $\begin{array}{c}\text { Coisas da Madrugada - } \\
\text { Um pouco da minha vida }\end{array}$ & $11 / 06 / 12$ & $11: 01$ & 159.672 & 10.405 & 202 & 2.110 \\
\hline $\begin{array}{c}\text { Coisas da Madrugada - } \\
\text { Anos sem Michael Jackson! }\end{array}$ & $25 / 06 / 12$ & $10: 44$ & 123.232 & 16.745 & 247 & 4.122 \\
\hline \begin{tabular}{c} 
Ano \\
\hline
\end{tabular}
\end{tabular}

FONTE: Elaborada pelo autor

De maneira geral, inferimos que os vídeos que contam com maior número de visualizações são aqueles que foram postados há mais tempo, justamente em função do período em que se encontram disponíveis para acesso por diversos usuários ${ }^{14}$. Os vídeos são curtos e não ultrapassam a duração de onze minutos, o que condiz com o ambiente em que estão disponibilizados. A periodicidade de postagem do material é, nos primórdios do canal, iniciado em julho de 2010, praticamente mensal. A partir de novembro de 2010, Neto fica um ano sem postar e retoma em dezembro de 2011. Durante o primeiro semestre de 2012, as postagens ocorrem apenas em fevereiro e em junho.

\footnotetext{
${ }^{14}$ Preferimos o termo usuários por se referir a pessoas que se cadastraram no YouTube, de modo que elas disponibilizam ao sistema seus dados pessoais, tais como: $e$-mail, idade, gênero sexual, localidade, entre outros. Por meio do login dos usuários, o site consegue aferir e precisar as características dos mesmos. 
De acordo com as estatísticas, deduzimos que a maior parte das audiências gostam dos vídeos (like) e, na maioria dos vídeos, não chega a $1 \%$ a quantidade de usuários que não gostaram (deslike) dos vídeos assistidos. Os comentários variam aproximadamente de menos de $1 \%$ a $3 \%$ das visualizações. Os vídeos adicionados como favoritos, por sua vez, representam menos de $1 \%$ do total de visualizações. Com relação aos vídeos mais acessados, é possível associarmos a classificação dos mesmos ao volume de visualizações. Isso quer dizer que vídeos que utilizam tags associadas à Felipe Neto e a celebridades, como Jô Soares e Harry Potter, por exemplo, são mais vistos em função dessas palavras-chaves serem mais comuns e recorrentes em sistemas de busca de conteúdo pela internet. Nesse caso, evidenciamos a reverberação de assuntos que estão ou estiveram em pauta em outros meios, como a televisão e o cinema.

Até o presente momento nos atemos aos dados quantitativos do material audiovisual de Neto, partimos agora para uma dimensão qualitativa dos vídeos, investigando os modos como Felipe performa ante diferentes audiências. O nosso interesse nesse conjunto de vídeos que pretendemos tratar se encontra na própria fala de Felipe Neto no primeiro vídeo da categoria ("Desabafo e coisas da Madrugada"):

\footnotetext{
Olá. É... São cinco e três da manhã nesse exato momento... de uma... terça-feira. Eu estou sem nada pra fazer, absolutamente sem nada pra fazer. Eu decidi ligar minha câmera porque... eu gosto de falar com vocês. Mesmo que isso signifique na verdade falar com a minha câmera... o que é muito esquizofrênico, mas eu gosto. E eu decidi gravar a câmera sem ter nenhum assunto em mente, sem ter nada realmente programado pra dizer... Falar um pouquinho da minha vida, falar como tão as coisas no momento. [...] Eu faço vídeo por um motivo muito simples: falar o que eu penso. Então, assim... eu criei uma espécie de um personagem pra poder falar as coisas que eu penso de uma forma meio explosiva mas nunca pensando que iria fazer tanto sucesso, então, agora... eu meio que carrego a responsabilidade desse sucesso dos meus vídeos. [...] (NETO, 2010).
}

A declaração acima, ou melhor, o desabafo de Felipe Neto, para utilizar uma expressão empregada por ele, nos dá a ver o caráter exibicionista de seu comportamento na internet. Por meio dos vídeos, Neto pode contar um pouco sobre a sua vida e falar o que pensa, como o faz no vídeo "Coisas da Madrugada - Um pouco da minha vida", em que ele relata porque é "um brasileiro que conseguiu vencer", descrevendo sua história, sua infância e alguns momentos específicos de sua trajetória. Cabe frisar, em especial sobre esse vídeo, que 
Neto registra seu depoimento em parceria ${ }^{15}$ com a campanha publicitária da Caixa Econômica Federal, como é dito ao início da gravação.

As narrativas de Felipe Neto, como eu-imagem (BRUNO, 2004), muitas vezes associadas à lógica midiática e mercadológica, seja em termos de repercussão em outros meios ou a celebrização do eu, contemplam o embaçamento das fronteires entre o público e o privado, como discutidos por Thompson (2008, 2010). Ao mostrar como cenário dos vídeos o quarto em que dorme, Neto exibe sua privacidade/intimidade, buscando aproximar-se de suas audiências. Por meio dessas imagens, como o prêmio VMB conquistado ou o cachorro, a namorada ou o amigo, o performer vincula-se ao grupo ao qual pertence, performando-o. Em outras palavras, Felipe consegue se identificar com suas audiências ao se dar a ver como elas, como pessoa comum, como um qualquer, mas não como qualquer um, já que em função do número de acessos e sua aparição em programas televisivos, podemos considerar que ele tornou-se uma celebridade.

A manutenção desse status é fortemente evidenciada pelo apelo que o vlogueiro endereça às audiências. Em vídeos mais recentes, após obter destaque nos media e ser consciente da visibilidade adquirida, Neto conclama os usuários a aderirem à sua performance. Para tanto, enfatiza nos vídeos que é preciso assistir e "curtir" os outros vídeos depositados no canal e os que estão por vir: "Eu vou fazer mais vídeos, então inscreva-se no canal" Desabafo e Coisas da Madrugada - Vlog Oficial ${ }^{16}$. Outros recursos retóricos empregados para garantir a fidelização das audiências são: "clique aqui para curtir", “clique aqui para adicionar como seu favorito" e "me adicione no Twitter". Além disso, o uso constante de palavrões em falas entrecortadas e atravessadas por momentos de silêncio ligam o comportamento de Felipe ao comportamento juvenil das audiências.

\section{Considerações Finais}

Suscintamente, pudemos apontar alguns aspectos da performance de Felipe Neto no YouTube - que necessitam de mais estudos - compreendendo que a prática performática não

\footnotetext{
${ }^{15}$ Os usuários (donos) de canais no YouTube podem ser convidados a se filiarem ao Programa de Parcerias do YouTube (http://www.youtube.com/partners?hl=pt) ou se filiarem voluntariamente. Ao aderirem ao programa, os usuários concordam em permitir que anúncios publicitários sejam veiculados em seus vídeos antes que o conteúdo dos mesmos seja visualizado. O valor a ser recebido mensalmente varia de acordo com o número de anúncios que serão veiculados nos canais e o número de vezes que eles serão assistidos por diferentes usuários. 30 mil filiados participam do Programa de Parcerias em 27 países. Dentre os diversos canais, podemos citar: Felipe Neto Vlog, Não Faz Sentido, 5inco Minutos (Kéfera Buchmann), Galo Frito, Mas Poxa Vida (PC Siqueira) (ROTHMAN, 2012).

${ }^{16}$ Disponível em: <http://www.youtube.com/watch?v=1wD8OOlcx_0> Acesso em: 10 jul. 2012.

Dispositiva

v. $1 \mathrm{n} .2$

nov.2012 / abr.2013
} 
se encontra em algo ou em alguém, mas sim na relação que passa a ser estabelecida entre aquele que realiza/executa a ação e aqueles que a observam e dela coparticipam. $\mathrm{O}$ rosto se apresenta como interface primordial para o contato visual atravessado pela câmera. A lente incorpora a função do espelho, em que o performer pode ver a si mesmo e aqueles que passam por ele. Narcisismo que visa alcançar o outro para com ele estabelecer um diálogo e assegurar sua condição existencial.

Apreendemos também que a internet tem se configurado como uma ambiência midiática propícia à apresentação pública de certas ações que visam cativar e atrair os olhares de vários sujeitos. Por meio da facilidade de acesso ao conteúdo ofertado, aquilo que anteriormente pertencia ao âmbito privado da vida, ao ambiente familiar, vê-se aberto e desnudado a estranhos que passam a integrar uma comunidade, uma tribo. Nesse sentido, podemos considerar, juntamente com Maffesoli (1998), que a cena contemporânea ${ }^{17}$ é marcada pelo perder-se no outro, de modo que "cada um só existe no e pelo olhar do outro, seja a tribo de afinidade, a alteridade da natureza ou o Grande Outro que é a divindade." (p. $12)$.

Falar com a câmera, tendo como referência esse ponto de vista, significa mais do que registrar uma performance em que se pode contar e expressar o que se pensa e o que se quer. A relação com a ferramenta, que metaforicamente representa um grande olho que capta a efemeridade e banalidade das situações cotidianas de sujeitos ordinários e que amplia os campos do visível, reconfigura os modos de estar juntos, que necessariamente passam por uma mediação técnica na contemporaneidade. Podemos dizer, assim, de uma sociabilidade mediatizada que tem sua dimensão imagética potencializada pelas possibilidades de vinculações e afetos que instaura. O performer, agente da e na performance, coloca-se entre a técnica e a prática, configurando-se como mediador das relações sociais atravessadas por imagens ${ }^{18}$, que de acordo com Maffesoli (1998) adquirem o estatuto de importantes constituidoras dos sujeitos sociais e da sociedade.

Através do espelho, como em Alice de Lewis Carroll, ou melhor, da lente da câmera, é possível ao agente agenciar encontros que abordam assuntos que interessam mutuamente o performer e as audiências que se formam em torno dele. Com isso, comunidades de interesses

\footnotetext{
${ }^{17}$ Michel Mafessoli (1998) emprega o termo "pós-modernidade" para se referir ao momento histórico e social que sucede o período denominado por vários teóricos como "modernidade" ou "pós-medievalidade" como ele utiliza. Preferimos a nomenclatura "contemporâneo" uma vez que o primeiro conceito é passível de múltiplas interpretações e abordagens. Apesar do termo que empregamos ser abstrato e pouco preciso, queremos fazer menção ao nosso tempo, um momento que se volta para pequenas narrativas específicas, para o retorno ao local, para a importância da tribo e para a colagem mitológica, como pontua Mafessoli (1998).

${ }^{18} \mathrm{O}$ conceito de imagens é mais abrangente que apenas a materialização física da realidade. Conferir: Maffesoli (1998).

Dispositiva

v. $1 \mathrm{n} .2$

nov.2012 / abr.2013
} 
são forjadas em interação e por meio da identificação daqueles que assistem e coparticipam da performance com aquele que realiza a ação. Identificação que muitas vezes leva à admiração ou ao desprezo - consequências intrínsecas à visibilidade. É preciso atentarmos aqui para o fato de que as performances sociais podem ocorrer em situações face a face também, como ressalta o sociólogo Erving Goffman (1985).

O que queremos enfatizar com nossa argumentação é que as imagens assumiram a posição de elementos primordiais do vínculo social (MAFFESOLI, 1998). Para retomarmos a concepção de espetáculo, tal como criticada por Debord (1977) e aprofundada por Sibilia (2008, 2010), compreendemos que o show do eu, bastante notório em reality shows, blogs e fotlologs e vlogs, tem sido um recurso de apresentação de si ao outro potencializado pelos media. Portanto, é preciso estarmos atentamos ao desdobrar das imagens e as relações sociais que elas medeiam a fim de sabermos e entendermos o contemporâneo.

\section{Referências}

ARRUDA, Byanka da Silva et al. A exposição do jovem na internet: um estudo sobre o caso Felipe Neto. In: Biblioteca on-line de Ciências da Comunicação (BOCC), 2011. Disponível em: <http://www.bocc.ubi.pt/pag/ arruda-et-al-a-exposicao-do-jovem-na-internet.pdf> Acesso em: 11 jan. 2012.

BRAGA, José Luiz. Sobre "mediatização"como processo interacional de referência. In: $15^{\circ}$ ENCONTRO ANUAL DA COMPÓS, 2006, UNESP, Bauru-SP, 6 a 9 de junho. Anais... São Paulo: COMPÓS, 2006. Disponível em: 〈http://www.compos.org.br/data/biblioteca_446.pdf> Acesso em: 10 abr. 2011.

BRUNO, Fernanda; PEDRO, Rosa. Entre aparecer e ser: tecnologia, espetáculo e subjetividade contemporânea. Intexto, Porto Alegre, UFRGS, v. 2, n. 11, p. 1-16, jul./dez. 2004. Disponível em: <http://seer.ufrgs.br/intexto/article/view/4080/4454> Acesso em: 05 jul. 2012.

CARLSON, Marvin. Performance: uma introdução crítica. Belo Horizonte: UFMG, 2010.

CONTROLE REMOTO. Voltamos a apresentar... 2010. Disponível em: <http://controle remototv.blogspot.com.br/ search?q=felipe+neto> Acesso em: 19 jun. 2012.

DEBORD, Guy. A sociedade do espetáculo. Rio de Janeiro: Contraponto, 1997.

FAUSTO NETO, Antônio. Fragmentos de uma analítica da midiatização. In: Matrizes, USP, São Paulo, v. 1, n. 2, abr. 2008, p. 89-105. Disponível em: <http://www.matrizes.usp.br/index. php/matrizes/article/view/88/136> Acesso em: 13 jun. 2011.

FELIPE NETO TEAM. 2012. Disponível em: <http://www.felipenetoteam.com/> Acesso em: 19 jun. 2012. 
GOFFMAN, Erving. A representação do eu na vida cotidiana. Petrópolis, RJ: Vozes, 1985.

HERSCHMANN, Micael. Espetacularização e alta visibilidade: a politização da cultura hiphop no Brasil contemporâneo. In: FREIRE FILHO, João; HERSCHMANN, Micael. (Orgs.). Comunicação, Cultura \& Consumo. A (des)construção do espetáculo contemporâneo. 1 ed. Rio de Janeiro: Ed. E-Papers, 2005, v. 1, p. 137-154. PDF p. 1-11. Disponível em:

$<$ http://www.pos.eco.ufrj.br/docentes/publicacoes/micael_espetacularizacao.pdf > Acesso em: 09 jul. 2012.

HERSCHMANN, Micael ; KISHINHEVSKY, Marcelo. A "geração podcasting” e os novos usos do rádio na sociedade do espetáculo e do entretenimento. Revista FAMECOS, Porto Alegre, v. 1, n. 37, p. 100-1007, dez. 2008. Disponível em: <http://revistaseletronicas.pucrs. br/ojs/index.php/revistafamecos/article/viewFile/4806/3610> Acesso em: 29 mai. 2012.

HJARVARD, Stig. Midiatização: teorizando a mídia como agente de mudança social e cultural. MATRIZES, USP, São Paulo, v. 5, n. 2, jan./jun. 2012, p. 53-91. Disponível em: <http://www.matrizes.usp.br/index.php/matrizes/article/view/338/pdf> Acesso em: 25 jun. 2012.

MAFFESOLI, Michel. Mediações simbólicas: a imagem como vínculo social. Revista FAMECOS, Porto Alegre, v. 1, n. 8, jul. 1998, p. 7-14. Disponível em: <http://revistas eletronicas.pucrs.br/ojs/index.php/revistafamecos/article/viewFile/5462/3963> Acesso em: 08 jul. 2012.

NETO, Felipe. Desabafo e coisas da madrugada. YouTube, 7 de julho de 2010. Disponível em: <http://www.youtube.com/watch? $\mathrm{v}=\mathrm{kpiVldk} 2 \mathrm{jjk} \&$ feature=player_profilepage $>$ Acesso em: 18 jun. 2011.

OXFORD DICTIONARY. Verbete avatar. 2012. Disponível em: <http://oxforddictionaries. com/definition/avatar?region=us\&q=avatar $>$ Acesso em: 19 jun. 2012.

ROTHMAN, Paula. Sorria você está sendo filmado. Revista Info, São Paulo, ed. 315, p. 5461, abril 2012.

SCHECHNER, Richard. O que é performance. In: O PERCEVEJO, Rio de Janeiro, ano 11, n. 12, p. 25-50, 2003.

SIBILIA, Paula. O artista como performer: Dilemas do eu espetacular nas artes contemporâneas. In: LABRA, Daniela (Org.). Performance presente futuro, vol. II. Rio de Janeiro: Ed. Aeroplano e Oi Futuro, 2010. p. 14-20.

SIBILIA, Paula. O show do eu: a intimidade como espetáculo. Rio de Janeiro: Nova Fronteira, 2008.

THOMPSON, John B. A nova visibilidade. MATRIZES, USP, São Paulo, v. 1, n. 2, abr. 2008, p. 15-38. Disponível em: <http://www.matrizes.usp.br/index.php/matrizes/article/view/ 82/124> Acesso em: 25 jun. 2012. 
THOMPSON, John B. Fronteiras cambiantes da vida pública e privada. MATRIZES, USP, São Paulo, v. 4, n. 1, jul./dez. 2010, p. 11-36. Disponível em: <http://www.matrizes.usp.br/ index.php/matrizes/article/view/176/295> Acesso em: 25 jun. 2012.

VERÓN, Eliseo. El cuerpo de las imágenes. Bogotá: Grupo Editorial Norma, 2001.

WIKIPÉDIA. Verbete Felipe Neto. 2011. Disponível em: <http://pt.wikipedia.org/wiki/ Felipe_Neto>Acesso em: 18. out. 2011.

Recebido em:16 jul. 2012

Aprovado em: 4 out. 2012 